\title{
Using high-pressure teflon bomb digestion in phosphorus determination of aquatic animals
}

\author{
Gergely Boros ${ }^{1,2 *}$, István Tátrai ${ }^{1}$ and Sándor A. Nagy ${ }^{2}$ \\ 1 Balaton Limnological Research Institute of the Hungarian Academy of Sciences, 8237, P.O. Box 35, Tihany, Hungary \\ 2 Department of Hydrobiology, University of Debrecen, 4032, Egyetem tér 1., Debrecen, Hungary
}

Received 9 October 2008; Accepted 12 December 2008

\begin{abstract}
High pressure and temperature were combined with the convenient mixture of acids to perform an effective digestion of samples from aquatic animals for phosphorus (P) analysis. Our results indicate that digestion in high-pressure bombs combined with concentrated acidic media can be a convenient way to yield all $\mathrm{P}$ stored in samples, and to produce accurate recoveries. Phosphorus recovery of a certified standard material $(94 \% \pm 15)$ and digestions of aquatic animal tissues confirmed the relevance of bomb decomposition, as well as its reliability compared to ashing and microwave oven digestion methods. Moreover, the applied digestion technique is easily manageable even in samples consisting of a few individuals. This method is relatively rapid, saves money and time, and is able to recover $\mathrm{P}$ from the most persistent components (e.g. bones, scales, fat) of aquatic animal tissues.
\end{abstract}

Key words: High-pressure digestion / phosphorus / fish / zooplankton / benthos

\section{Introduction}

Increased knowledge about the nutrient content of aquatic animals is important for understanding their role in cycling, transport and storage of nutrients. Major nutrients, such as carbon and nitrogen can be measured in dried-homogenized samples with good accuracy and precision in a relatively short time using carbon-hydrogennitrogen analyzers (Tanner et al., 1999; Sterner and George, 2000; Pilati and Vanni, 2007; Le Loc'h et al., 2008). In contrast, phosphorus (P) analysis is more timeconsuming and requires that animal tissues are digested before colorimetric measurement. The traditional standard method for determination of $\mathrm{P}$ is performed by oxidizing sample total phosphorus content to dissolved orthophosphate by digestion and colorimetric determination of liberated dissolved orthophosphate ions (Colina et al., 1996). The principle of the colorimetric measurement is the formation of 1,2-molybdophosphoric acid which is reduced to the phosphomolybdenum blue complex in the presence of reducing agent. The intensity of the blue colour is proportional to the amount of orthophosphate ions incorporated into the complex and hence, the reacted orthophosphate can be determined (Jarvie et al., 2002). However, the molar ratio of $\left[\mathrm{H}^{+}\right]$and $\left[\mathrm{MoO}_{4}{ }^{2-}\right]$

\footnotetext{
* Corresponding author: borosg@tres.blki.hu
}

may influence the outcome of colorimetric measurements and induce "non-phosphate sensitized $\mathrm{MoO}_{4}{ }^{2-}$ ion reduction" (Pai et al., 1990).

For digestion, a combination of sulphuric acid and nitric acid is proven as an effective tool (Brown et al., 1973; Sadiq and Zaidi, 1983; Colina et al., 1996), whilst higher pressure of a closed and heated system has a strong positive influence on the digestion of persistent materials (Schnitzer et al., 1995). Scientists use various digestion protocols for the same sample types and the results may not be comparable among procedures. The diversity of methods used to digest tissues from aquatic animals illustrates well this variety. For instance, Higgins et al. (2006) determined $\mathrm{P}$ content by ashing samples in a muffle furnace, followed by hydrochloric acid digestion. Sterner and George (2000) used ashing as well, but dissolved the ash in diluted $(0.3 \mathrm{~N})$ nitric acid. Hendrixson et al. (2007) used hot $10 \mathrm{~N}$ sulphuric acid, and Sereda et al. (2008) used $70 \%$ nitric acid for digestion of fish in the same procedure.

The so-called wet digestion method, applied when ashing is not included in the process, is also used widely. Frost et al. (2003) digested aquatic invertebrate samples by autoclaving with a potassium-persulfate digestion reagent. Tanner et al. (1999, 2000) and Reis et al. (2008) used concentrated acids and microwave oven treatment to digest dried biological samples. These procedures are 
based on the joint capacity of heat, pressure and oxidizing media to disassemble sample materials.

The same principle is relevant for high-pressure bomb digestion, which has been successfully applied in sediment $\mathrm{P}$ digestion (Colina et al., 1996). High pressure bombs are commonly used tools in the wet digestion of biological samples in heavy metal determination (Farkas et al., 2002, 2003; Ringmann et al., 2002). However, we have not found any references regarding the use of this method in $\mathrm{P}$ analysis of aquatic animal samples.

To confirm the validity of teflon bomb digestion technique in $\mathrm{P}$ content analyses, we tested the digestibility and recovery rate of a certified standard material and the results were compared with the efficiency of the commonly used "ashing in muffle furnace" and "microwave oven digestion" methods. In addition, we have digested fish, zoobenthos, and zooplankton samples and compared the obtained $\mathrm{P}$ contents to those available in the literature on the same taxonomic groups being digested by other methods.

\section{Materials and methods}

Four different samples were analyzed in our study: pork muscle standard (NCS ZC 81001, China National Analyst Centre for Iron and Steel) with certified P content $(0.813 \% \pm 0.031)$, homogenized whole body of a cyprinid fish, Prussian carp (Carassius auratus L., $\mathrm{TL}=44 \mathrm{~cm}$, $\mathrm{W}=1660 \mathrm{~g}$ ), macro-zoobenthos (chironomid larvae) and cladoceran zooplankton. All samples were dried to a constant weight at $65^{\circ} \mathrm{C}$ and milled to a fine powder by an electric grinder. To ensure homogenization, samples were passed twice through the grinder. Before weighing, samples were ground again with a mortar and pestle. The pork muscle standard was homogenized to a fine powder by the producer company. Teflon vessels and glassware used in measurements were washed with concentrated potassium dichromate $\left(\mathrm{K}_{2} \mathrm{Cr}_{2} \mathrm{O}_{7}\right)$ followed by a de-ionized water rinse. All chemicals were analytical reagent or puriss grade.

For sample digestion, our own, so-called high-pressure teflon bombs were used, which were manufactured at the University of Pannonia, Hungary. The construction is similar to the General Purpose Acid Digestion Bombs, distributed by Parr Instrument Company, USA. A teflon bomb consists of an aluminium holder, a teflon and aluminium cap with a screw-topped closing system and a removable teflon vessel $(100 \mathrm{~mL}$ volume, $\mathrm{d}=4.2 \mathrm{~cm}$, $1=7 \mathrm{~cm}$ ) inside (Fig. 1).

Dried samples (150-300 mg) were weighed to place in the teflon vessel, using a Sartorius BA 210S analytical balance, then $10 \mathrm{~mL}$ of acid mixture $(96 \mathrm{~m} \%$ sulphuric acid: $65 \mathrm{~m} \%$ nitric acid; 3:2) were added. Vessels were capped, placed into their aluminium holder and closed tightly with the screw system. In addition to bombs with samples, each digestion run contained a blank run as a control (to detect the background with $10 \mathrm{~mL}$ of acid mixture and free of biological material). Bombs were

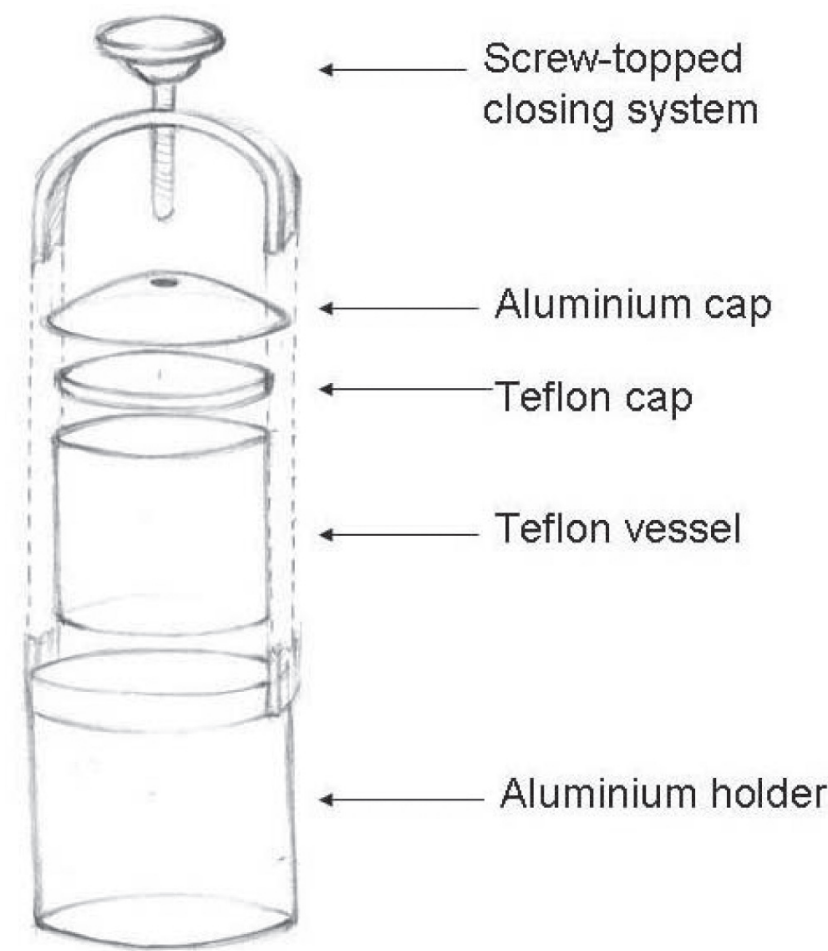

Fig. 1. Sketch of the high-pressure teflon bomb used for digestion of aquatic animal samples.

heated to $100{ }^{\circ} \mathrm{C}$ on an electric oven plate for $4 \mathrm{~h}$. Pressure in the bombs was not defined. Following cooling, vessels were opened in a fume hood and $0.5 \mathrm{~mL}$ digested sub samples were pipetted into scintillation vials with three replicates from each bomb. Subsequently, $9.5 \mathrm{~mL}$ of de-ionized water was added to the sub samples, as the first twenty-fold dilution step to complete the acid hydrolysis. Samples were stored in a dark place at room temperature overnight, then $0.5 \mathrm{~mL}$ was pipetted from the diluted solution and $9.5 \mathrm{~mL}$ de-ionized water was added. Final dilution of samples was four hundred-fold and after this step, they were ready for P-content determination.

Phosphorus content was measured spectrophotometricaly at $880 \mathrm{~nm}$ (Shimadzu UV 160-A spectrophotometer) using the conventional ammonium molybdate method (Strickland and Parsons, 1972). Relatively low $(<60)$ molar ratios between $\left[\mathrm{H}^{+}\right]:\left[\mathrm{MoO}_{4}{ }^{2-}\right]$ might result in self-reduction of the $\mathrm{MoO}_{4}{ }^{2-}$ ion to form a molybdenum blue colour independent of the $\mathrm{P}$ concentration (Going and Eisenreich, 1974; Pai et al., 1990). As our digesting reagents were concentrated acids and $\mathrm{pH}$ was relatively low in samples, we relied on the non-phosphate sensitized $\mathrm{MoO}_{4}{ }^{2-}$ ion reduction. Thus, mean absorbance measured in the blanks was subtracted from the absorbance of the samples. Hereby, we could eliminate the background absorbance produced by the digestion reagents. To get precise data from each subsample, we calculated the mean and standard deviation of three sub-replicates. 
Table 1. Comparisons of P-contents of a cyprinid fish (Prussian carp), benthic invertebrates (chironomids) and cladoceran plankton measured following high-pressure bomb digestion in our study and that of other digesting procedures.

\begin{tabular}{|c|c|c|}
\hline & $\begin{array}{l}\text { High-pressure bomb digestion (this study) } \\
\times \text { mean } 1 \pm \mathrm{SD}\left(\text { dry w }^{-1}, \%\right)(\min -\max ; n)\end{array}$ & $\begin{array}{l}\text { Other digesting methods } \\
\times \text { mean } 1 \pm \mathrm{SD}\left(\text { dry w }^{-1}, \%\right) \text { or range }\end{array}$ \\
\hline Cyprinid fish & $\begin{array}{c}2.70 \pm 0.32 \\
(2.30-3.30 ; 7)\end{array}$ & $\begin{array}{c}2.71 \pm 0.26 \dagger(\text { Penczak and Tátrai, 1985) } \\
0.80-3.20 * \text { (Sterner and George, } 2000) \\
2.40-3.60 * \text { (Hendrixson et al., } 2007) \\
2.10-4.20 * \text { (Sereda et al., 2008) }\end{array}$ \\
\hline Benthic invertebrates-chironomids & $\begin{array}{l}1.04 \pm 0.10 \\
(0.90-1.15 ; 7)\end{array}$ & $0.85 \pm 0.17 * *($ Frost et al., 2003) \\
\hline Cladoceran plankton & $\begin{array}{l}1.30 \pm 0.19 \\
(0.99-1.54 ; 7)\end{array}$ & $\begin{array}{c}1.4 \pm 0.2^{* *}(\text { Andersen and Hessen, 1991) } \\
1.2-1.4^{* *} \text { (Walve and Larsson, 1999) }\end{array}$ \\
\hline
\end{tabular}

Digestion methods: * ashing and acid hydrolisation; ** potassium-persulfate digestion; $\uparrow$ no reference for applied digestion.

\section{Results}

High-pressure digestion carried out in our teflon bombs in concentrated acids resulted in high recovery rate $(\bar{x} \pm 1 \mathrm{SD} ; 94 \pm 15 \%$, range: $79-115 \%, n=9)$ for pork muscle standard. Blank values, measured in the bombs with digesting chemicals and free of biological material resulted in a relatively high absorbance $(92 \pm$ $2.9 \mu \mathrm{g}$ P. $\left.\mathrm{L}^{-1}\right)$. This background was then used for correction of our measured P-contents.

$\mathrm{P}$ contents of cyprinid fish, benthic invertebrates (chironomids) and cladoceran plankton digested with the teflon bomb method are presented in Table 1. Our measured values proved to be comparable with those digested either by ashing or potassium-persulfate.

\section{Discussion}

Our results indicate that digestion in our high-pressure teflon bomb combined with concentrated acidic media can be a convenient way to yield total $\mathrm{P}$ content of various sample types and produce accurate recoveries. Mean recovery rate for standard material is similar to that of obtained following microwave oven digestion (90-95\%) and is by $14 \%$ higher than the recovery rate $(80 \%)$ found using ashing method combined with nitric acid hydrolysis (Tanner et al., 1999). Mean recovery from standard material was close to the certified value following correction with the blank value, which supports the theory of P-independent $\mathrm{MoO}_{4}{ }^{2-}$ ion reduction (Going and Eisenreich, 1974; Pai et al., 1990). We found that acid background elimination in the evaluation of the results can be a reliable way to calculate $\mathrm{P}$ content after digestion and colorimetric measurements.

Strong oxidation capacity of concentrated acids combined with high pressure and temperature resulted in digestion of the most recalcitrant materials such as fat, bony particles, scales or chitin. Moreover, there were no particulate sample remains in our teflon vessels after digestion. Ashing, a widespread method prior to colorimetric measurements (Sterner and George, 2000; Hendrixson et al., 2007; Sereda et al., 2008) decomposes complex and recalcitrant materials and solves the problem of absolute homogenization. Procedure of ashing may reduce sample mass by an order of magnitude, however, in case of small sample size (e.g. 1-2 individuals of macroinvertebrates or few zooplankton) it is not precisely applicable as ash is usually reweighed for $\mathrm{P}$ analysis. Sample digestion in our high-pressure teflon bomb is manageable even in case of samples consisting of few individuals only. Moreover, high-pressure bomb digestion is relatively rapid and the expenses of the analysis are low, which ensures a widespread application of this method.

The variety in different $\mathrm{P}$ digestion methods clearly reveals that researchers are not consistent in this issue (Tanner et al., 1999; Sterner and George, 2000; Sereda et al., 2008), thus we support international standardization to achieve results comparable among laboratories. We have broadened the application of high-pressure bomb digestion to give an alternative tool and reference for limnologists doing measurements on $\mathrm{P}$ stoichiometry of any kind of aquatic animals.

Acknowledgements. The authors are grateful for the comments and suggestions to Prof. Mike Vanni, Prof. Martin Søndergaard, and to an anonymous reviewer. National Research Fund OTKA T 048758 supported this study.

\section{References}

Andersen T. and Hessen D.O., 1991. Carbon, nitrogen, and phosphorus content of freshwater zooplankton. Limnol. Oceanogr., 36, 807-814.

Brown H.G., Hensley C.P. and Thale J.E., 1973. Low-temperature digestion method for fish tissue and sediment prior to total mercury analysis. Transactions of the Kansas Academy of Science, 76, 4-8.

Colina M., Ledo H., Gutiérrez E., Villalobos E. and Marín J., 1996. Determination of total phosphorus in sediments by means of high-pressure bombs and ion chromatography. J. Chromatogr., 739, 223-227.

Farkas A., Salánki J. and Specziár A., 2002. Relation between growth and the heavy metal concentration in organs of bream Abramis brama L. populating Lake Balaton. Arch. Environ. Contam. Toxicol., 43, 236-243.

Farkas A., Salánki J. and Specziár A., 2003. Age- and size specific patterns of heavy metals in the organs of freshwater 
fish Abramis brama L. populating a low-contaminated site. Wat. Res., 37, 959-964.

Frost P.C., Tank S.E., Turner M.A. and Elser J.J., 2003. Elemental composition of littoral invertebrates from oligortophic and eutrophic Canadian lakes. J. N. Am. Benthol. Soc., 22, 51-62.

Going J.E. and Eisenreich S.J., 1974. Spectrophotometric studies of reduced molybdoantimonylphosphoric acid. Anal. Chim. Acta, 70, 95-106.

Hendrixson H.A., Sterner R.W. and Kay A.D., 2007. Elemental stoichiometry of freshwater fishes in relation to phylogeny, allometry and ecology. J. Fish Biol., 70, 121-140.

Higgins K.A., Vanni M.J. and González M.J., 2006. Detritivory and the stoichiometry of nutrient cycling by a dominant fish species in lakes of varying productivity. Oikos, 114, 419430.

Jarvie H.P., Withers P.J.A. and Neal C., 2002. Review of robust measurement of phosphorus in river water: sampling, storage, fractionation and sensitivity. Hydrol. Earth Sys. Sci., 6, 113-132.

Le Loc'h F., Hily C. and Grall J., 2008. Benthic community and food web structure on the continental shelf of the Bay of Biscay (North Eastern Atlantic) revealed by stable isotopes analysis. J. Marine Syst., 72, 17-34.

Pai S., Yang C.C. and Riley J.P., 1990. Effects of acidity and molybdate concentration on the kinetics of the formation of the phosphoantimonylmolybdenum blue complex. Anal. Chim. Acta, 229, 115-120.

Penczak T. and Tátrai I., 1985. Contribution of bream, Abramis brama (L.), to the nutrient dynamics of Lake Balaton. Hydrobiologia, 126, 59-64.

Pilati A. and Vanni M.J., 2007. Ontogeny, diet shifts, and nutrient stoichiometry in fish. Oikos, 116, 1663-1674.

Reis P.A., Valente L.M.P. and Almeida C.M.R., 2008. A fast and simple methodology for determination of yttrium as an inert marker in digestibility studies. Food Chem., 108, 1094 1098.

Ringmann S., Boch K., Marquardt W., Schuster M., Schlemmer G. and Kainrath P., 2002. Microwave-assisted digestion of organoarsenic compounds for the determination of total arsenic in aqueous, biological, and sediment samples using flow injection hybride generation electrothermal atomic absorption spectrometry. Anal. Chim. Acta, 452, 207-215.

Sadiq M. and Zaidi T.H., 1983. A study of various factors affecting digestion of fish tissue prior to mercury determination. Int. J. Environ. Anal. Chem., 16, 57-66.

Schnitzer G., Soubelet A., Testu C. and Chafey C., 1995. Comparison of open and closed focused microwave digestions in view of total mercury determination by cold vapour atomic absorption spectrometry. Microchim. Acta, 119, 199-209.

Sereda J.M., Hudson J.J., Taylor W.D. and Demers E., 2008. Fish as sources and sinks of nutrients in lakes. Freshwat. Biol., 53, 278-289.

Sterner R.W. and George N.B., 2000. Carbon, nitrogen and phosphorus stoichiometry of cyprinid fishes. Ecology, 81, 127-140.

Strickland J.D.H. and Parsons T.R., 1972. A practical handbook of seawater analysis. Fish. Res. Board Can. Bull., 167, Ottawa, Canada, 310 p.

Tanner D.K., Leonard E.N. and Brazner J.C., 1999. Microwave digestion method for phosphorus determination of fish tissue. Limnol. Oceanogr., 44, 708-709.

Tanner D.K., Brazner J.C. and Brady V.J., 2000. Factors influencing carbon, nitrogen, and phosphorus content of fish from a Lake Superior coastal wetland. Can. J. Fish. Aquat. Sci., 57, 1243-1251.

Walve J. and Larsson U., 1999. Carbon, nitrogen and phosphorus stoichiometry of crustacean zooplankton in the Baltic Sea: implications for nutrient recycling. J. Plank. Res., 21, 2309-2321 